\title{
Kuloğlu Şeyh Hacı İlyas'ın Dîvân-ı Mesâbih Adlı Eseri Üzerine Bir Değerlendirme
}

\author{
Niyazi ADIGÜZEL ${ }^{1}$
}

\begin{abstract}
$\ddot{\mathbf{O} z}$
Kuloğlu Şeyh Hacı İlyas [?-1657/1658], şuara tezkirelerinde adı hiç geçmeyen, 17.yüzyılın ikinci yarısında yaşamını sürdürmüş ve çok sayıda eserler vermiş bir Klasik Türk Edebiyatı şairidir. Halvetiyye tarikatının Ahmediyye kolunun Uşşâkiyye şubesine bağlı bir şeyh olması ve mutasavvıf kişiliği gereği yazdığı eserler de dinî-tasavvufî içeriklidir. Çok sayıda manzume içeren eserleri şunlardır: Mevlid-i Nebî, Etvâr-ı Seb’a, Silsile-nâme, Dîvân-ı Hümâyûn, Bâğ-ı Behişt ve Dîvân-ı Mesâbîh. Bu çalışmada ele aldığımız Divân-ı Mesâbih, İslam âleminde meşhur olan Ferrâ el-Begavî [ö. 516/1122] tarafından kaleme alınmış Mesâbîhü’s-Sünne adlı hadis kitabının Âlim Sinan Efendi tarafindan Türkçeye tercüme edilen metninden seçilmiş hadislerin manzum olarak tercüme edilmiş şeklidir. Eserdeki şiirler kaside nazım şekliyle yazılmıştır. Kasidelerin revi harflerine göre alfabetik olarak tertip edilen eser, klasik tertip usulüne uygun olarak tevhid, münâcât, naat, dört halife methi ve Sultan IV. Murad methi manzumeleriyle başlamaktadır. Geri kalanı muhtelif hadislerin açıklaması olan manzumelerden oluşmaktadır. Eserde önce söz başlarına tercümesi yapılacak hadisler yazılıp sonra 20 beyitlik bir kasideyle ilgili hadisin tercümesi/açıklaması yapılmıştır. Her bir hadis için ayrı bir kaside yazılmıştır. Oldukça hacimli olan eserde yaklaşık 8.500 beyit bulunmaktadır. Türk Edebiyatında manzum kırk hadis tercümeleri sıklıkla kaleme alınmıştır ancak Kuloğlu gibi bütün bir divanın hadislerin tercüme edildiği yirmişer beyitlik şiirlerden oluştuğu bir örnek bulunmamaktadır. Bu yönüyle eser dikkate değer sıra dışı bir örnek teşkil etmektedir.
\end{abstract}

Anahtar kelimeler: Kuloğlu Şeyh Hacı İlyas, Divan-ı Mesâbih, Tasavvuf, Klasik Türk Edebiyatı.

\section{A Study on Dîvân-1 Mesâbih by Kuloğlu Sheikh Hacı İlyas}

\begin{abstract}
Kuloğlu Sheikh Hacı İlyas [?-1657/1658] is a Classical Turkish Literature poet with many works who lived in the second half of $17^{\text {th }}$ century. However, his name is not in the collection of biographies of poets. His works are religious since he is a sheikh belonging to Halvetiyye cult. His poems are as follows: Mevlid-i Nebî, Etvâr-ı Seb’a, Silsile-nâme, Dîvân-ı Hümâyûn, Bâğ-ı Behişt ve Dîvân-ı Mesâbîh. In this paper, Dîvân-ı Mesâbîh is studied. It is the poetical translation of hadiths that was picked from Mesâbîhü's-Sünne written by Ferrâ el-Begavî and translated by Âlim Sinan Efendi. The poems in the work are written in ode verses. The odes are arranged in alphabetical order in revi letters (the letters making the rhyme). The work begins with tevhid (poems praising the oneness of Allah), münâcât (poems for praying Allah), naat (poems praising Prophet Mohammed), acclaim of four Khalifas and Sultan IV. Murat. The rest is the poems of various hadiths. In this paper, first, hadiths, which are to be translated, are given. Then, the hadith, which is about an ode with 20 couplets, is translated and explained. For each hadith, an ode is written. In such a big work, there are 8.500 couplets. In Turkish Literature, there are many poetical translations but there is no other example like Kuloğlu's work. Hence, his work seems remarkable.
\end{abstract}

Dr. Öğr. Üye., Kırklareli Üniversitesi, Fen Edebiyat Fakültesi, Türk Dili ve Edebiyatı Bölümü, niyaziadiguzel@gmail.com [Makale kayit tarihi: 3.7.2018-kabul tarihi: 15.8.2018] 
Key words: Kuloglu Sheikh Hadji Ilyas, Dîvân-ı Mesâbih, Sufism, classical Turkish literature.

\section{Kuloğlu Şeyh Hacı İlyas'ın Hayatı ve Eserleri}

Kuloğlu Şeyh Hacı İlyas 17. yüzyılda yaşamış ve oldukça fazla eser vermiş bir klasik Türk edebiyatı şairidir. Ancak velut bir şair olmasına rağmen şuara tezkirelerinde adına rastlanmamaktadır. Son dönem kaynaklarında ise hakkında yanlış bilgiler verilmiştir. Osmanlı müellifleri eserinin sahibi Bursalı Mehmet Tahir onun ismini Mustafa olarak belirtmiş ve hakkında şu bilgileri vermiştir:

Sultan Murad-ı Rabi’ devri ricalinden ve Halvetiyye-i Uşşakiyye meşayihinden Gelibolulu Âlim Sinan Efendi hulefasından âşı u fâzıl bir zattır. Mesâbih-i şerifi nazmen tercüme eylemiştir. 1045 tarihinde ikmal ederek Divan-ı Hümayun adını verdiği Divan-ı Kebiri de vardır ki ikisinin de nüshaları Kütübhane-i Umumide mevcuttur. Bir de Mevlid-i Nebi manzumesi vardır. (Bursalı, 1333: 146-147)

Aynı şekilde Vasfi Mahir Kocatürk de ismini yanlış olarak Mustafa vermiş ve onun bütün manzumelerinde 14. asırdan 17. asra kadar dinî edebiyat havalarının esmekte olduğunu bunun yanı sıra bazen Yunus ve Âşı Paşa yolunda ilahiye benzer beyitler bazen de 17. asır divan şiiri dilinin dinî terennümlerinin (Kocatürk, 1970: 475-477) bulunduğunu belirtmiştir.

Sefine-i Evliya-yı Ebrar adlı eserinde Hüseyin Vassaf, Kuloğlu'nun Uşşâkî şeyhi Âlim Sinan Efendi’nin halifesi olduğunu, onun yazmış olduğu Mesâbih’i nazmen tercüme ettiğini, Divan-ı Hümayun isimli büyük bir divanının bulunduğunu ve Mevlid-i Nebi isimli bir manzumesinin de olduğunu (Vassaf, t.siz: 238) dile getirmiştir.

Necla Pekolcay ise Kuloğlu'na, yazmış olduğu Mevlid-i Nebi dolayısıyla eserinde yer vermiş ancak o da adını Kuloğlu Mustafa (Pekolcay, 2005: 4) şeklinde zikretmiştir. Bu karışıklık aynı yüzyılda yaşamış olan Kuloğlu Mustafa isimli halk şairiyle aynı mahlası kullanmış olmasından kaynaklanmaktadır. Oysa Kuloğlu Şeyh Hacı İlyas bir tarikat şeyhidir. Yazmış olduğu Divan-ı Mesâbih'in ferağ kaydında ve ser levhasında künyesini Şeyh Hacı İlyas şeklinde açıkça belirtmiştir. ${ }^{2}$

Bursalı Mehmet Tahir ve Hüseyin Vassaf'ın da belirttiği gibi Kuloğlu, Uşşakiyye şeyhi Âlim Sinan Efendi'nin halifesidir. Bu durum eserinden de anlaşılmaktadır. Mesâbih-i Şerif'de tevhid, naat ve dört halife övgüsünden sonra Sultan Murad'ın övgüsünden de önce 7. manzume olarak Âlim Sinan Efendi’ye fahru's-sulehâ zübdetü'l-'urefâ hazret-i Şeyh Sinân Efendi a'nî 'azîz-i men”3 başlığıyla bir methiye yazmıştır. El-hâcc şeklindeki lakabından hacca gitmiş olduğu anlaşılmaktadır. Arapça ve Farsçayı rahatlıkla kullanabildiği eserlerinden anlaşılmaktadır. Buradan hareketle iyi bir eğitim almış olduğu söylenebilir. Kaynaklarda doğum tarihiyle ilgili herhangi bir bilgi bulunmamaktadır. Kuloğlu'nun Bâğ-ı Behişt adlı eseri üzerinde bir doktora çalışması yapmış olan Bünyamin Taş diğer eserlerinden de hareketle tahmini olarak 1580-160o yılları arasında doğmuş olabileceği (Taş, 2014: 27) sonucuna varmıştır. Kuloğlu'nun ölüm tarihiyle ilgili de fazla bir bilgi bulunmamaktadır. Sadece Bayezit Devlet Kütüphanesinde bulunan Divan-ı Hümayun adlı eserinin 281 sayfasında yer alan fevâid kaydında 1068 (1657-58) yılında vefat ettiği yazılıdır.4

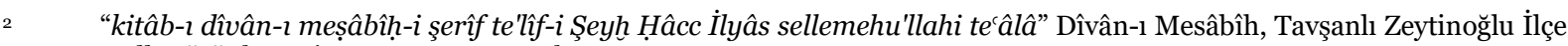
Halk Kütüphanesi, No:43 Ze 362, v. 1b

Dîvân-1 Mesâbîh, v. 3b

Şeyh Hacı İlyas (1045/1635), Dîvân-ı Hümâyûn, Beyazıt Devlet Kütüphanesi, No: 3596
}

Adres
Adress 1

Kirklareli University, Faculty of Arts and Sciences, Department of Turkish Language and Literature, Kayalı Campus-Kırklareli/TURKEY e-mail: editor@rumelide.com 


\section{Eserleri}

\section{Mevlid-i Nebî}

Kuloğlu'nun manzum bir eseri olarak Bursalı Mehmet Tahir, Hüseyin Vassaf ve Necla Pekolcay tarafından adı zikredilen bu esere kütüphane kayıtlarında rastlanılmamıştır. Necla Pekolcay, eserin bir nüshasının bulunduğunu söylemekle birlikte bu nüshanın yerini belirtmemiştir. (2005: 4) Mevlid manzumeleriyle ilgili müstakil bir çalışma yapan M. Fatih Köksal da bu nüshayı tespit edememiştir. (2011: 67)

\section{Etvâr-1 Seb’a}

Eser, mutasavviflar tarafından nefsin mertebeleri olarak kabul edilen yedi makamla (nefs-i emmâre, nefs-i levvâme, nefs-i mülhime, nefs-i mutmainne, nefs-i râzıyye, nefs-i marzıyye ve nefs-i kâmile) ilgilidir. Söz konusu makamların her biri manzum olarak açılanmıştır. Eser, 1000 beyit civarında olup 1030 (1620/21) yılında kaleme alınmıştır. Eserin bilinen iki nüshası vardır. Bunlardan biri Manisa İl Halk Kütüphanesi’nde (Arşiv no: 45Hk 6266) Bâğ-ı Behişt adlı eserle aynı cilt içinde $251^{\mathrm{b}}-308^{\mathrm{a}}$ varakları arasında, diğeri ise Süleymaniye Kütüphanesi Reşit Efendi Koleksiyonu'nda (Arşiv no: 1003) 350-392 numaralı varaklar arasında yer almaktadır. Kuloğlu’nun bu eseri 2012 yılında Necdet Şengün tarafından yayımlanmıştır. ${ }^{5}$

\section{Silsile-nâme}

Eser, Kuloğlu'nun yaşadığı zamana kadar Halvetî Uşşâkî silsilesine dâhil edilen şeyhlerin künyelerini vermektedir. Mesnevi nazım şekliyle yazılmıştır ve 39 beyitten müteşekkildir. Eserde $\mathrm{Hz}$. Muhammed'den sonra onun manevî varisleri olarak sırasıyla dört halifenin ismi ve onlardan sonra da evliyanın rehberi olarak tabiinden Hasan-ı Basri’nin ismi anılır. Hasan-ı Basri'den sonra ise sırasıyla şu isimler zikredilmiştir: Habîb Acemî, Dâvûd-ı Tâî, Ma'rûf-ı Kerhî, Serîrü'l-Sakatî, Cüneyd-i Bağdâdî, Mimşâd Dineverî, Muhammed Dineverî, Kâdî Muhyiddîn, Ebu'l-Necîb, Şeyh Kutbuddîn, Şeyh Rükneddîn, Şeyh Şihâbüddîn, Şeyh Cemâleddîn, Şeyh İbrâhîm, Muhammed Halvetî, Pîr Ömer Halvetî, Âhî Mîrîm, Îsâ Çelebi, Şeyh İzzeddîn, Şeyh Sadreddîn, Seyyid Yahyâ, Pîr Muhammed, Şeyh Tacüddîn, Şeyh Alauddîn, Şeyh Yigitbaşı, Hâcî Karamanî, Ümmî Sinân İstanbulî, Nasûh Abdussamed, Şeyh Ahmed, Şeyh Hüsâm Uşşâkî, Şeyh Memican, Ömer Karîbî, Şeyh Sinân (Âlim Sinân Efendi). Eserin yazılış tarihine dair bir kayıt yoktur. Tek nüshası Bâğ-ı Behişt ve Etvâr-ı Seb’a nüshalarıyla aynı cilt içinde $309^{\mathrm{a}}-310^{\mathrm{a}}$ varakları arasında Manisa İl Halk Kütüphanesi’nde (Arşiv no: $45 \mathrm{Hk}$ 6266) bulunmaktadır.

\section{Dîvân-1 Hümayûn}

Tamamı kasidelerden oluşan bir divandır. Eser, yaklaşık 450 tane manzume içermektedir. $\mathrm{Bu}$ manzumelerin 19 tanesi Farsça, geri kalanı ise Türkçedir. Divan, şiirlerin revi harflerine göre alfabetik olarak tertip edilmiştir. Divandaki şiirlerin hemen hepsinde konu olarak tasavvufî aşk işlenmiştir. Eserdeki ilk üç şiir tasavvufî aşkı işlerken dördüncü ve beşinci şiirler naat, altıncı şiir ise IV. Murat övgüsünde yazılmış bir methiyedir. Eser, tasavvufî ıstılahları bolca işlemekle birlikte şiirler, bu tür

5 Kuloğlu Şeyh İlyâs, Etvâr-ı Seb’a, (2015) Haz: Necdet Şengün, İlahiyat Yayınları, 2. Basım, Ankara, 286 s

\begin{tabular}{|c|c|}
\hline $\begin{array}{r}\text { Üniversitesi, Fen Edebiyat } \\
\text { Bölümü, Kayal }\end{array}$ & $\begin{array}{l}\text { rkish Language and Literature, Kayalı Campus-Kır } \\
\text { mail: editor@rumelide.com }\end{array}$ \\
\hline
\end{tabular}


eserlerin çoğunda olduğu gibi kuru bir didaktik üslupla yazılmamıştır. Hicrî 1045 yllında Rebiülevvel ayının 15. gününde (29/o8/1635) tamamlanan eserin tek nüshası Beyazıt Devlet Kütüphanesi’ndedir.6

\section{Bâğ-1 Behişt}

Bu eser de tıpkı Dîvân-ı Hümayun gibi tamamı kasidelerden oluşan hacimli bir eserdir. İçerisinde 403 kaside bulunmaktadır. Eser, kasidelerin revi harflerine göre alfabetik olarak tertip edilmiştir. Bâğ-ı Behişt, son iki kaside hariç baştan sona ayetler bağlamında nazmedilen bir eser olmakla birlikte şiirlerin muhtevası belirlenirken klasik tertip usulü gözetilmiştir. Buna göre ilk üç şiir münâcât; dördüncü şiir tevhîd; beşinci ve altıncı şiirler naat; sırasıyla yedi, sekiz, dokuz ve onuncu şiirler Hz. Ebubekir, Hz. Ömer, Hz. Osman ve Hz. Ali övgüsünde birer methiye; on birinci şiir ise IV. Murat övgüsünde bir methiyedir. Bu ilk on şiirin her biri de tıpkı eserdeki diğer şiirler gibi bir ayet bağlamında yazılmıştır. Eserde önce ilgili ayet, sonra o ayetten mülhem olan şiir yazılmıştır. Eser, bu yönüyle bir bakıma oldukça serbest bir tefsir özelliği arz etmektedir. (Taş, 2013: 11) Toplamda 403 kaside ihtiva eden eserde bu kasidelerin 401 tanesi Kur'an'dan bir ayetle ilgili olurken hatime kasidesinden önceki kaside "Benim ümmetimin âlimleri İsrailoğullarının nebileri gibidir." hadisi bağlamında yazılmıştır. Son kaside ise önce de ifade edildiği üzere bir hatime manzumesidir. Bu manzumede şair; eserini neden, nasıl, ne zaman yazdığını ve eserine verdiği ismi açıllamaktadır. Buna göre şair, eserini cihana bir yadigâr bırakarak Allah'ın rızasını kazanmak için her bir ayete bir kaside yazmak suretiyle 1047 (1638) yılının Ramazan ayında Kadir Gecesi’ne denk gelen bir Cuma günü bitirerek ona Bâğ-ı Behişt adını vermiştir. (Taş, 2014: 26) Bu eser, 2014 yılında Bünyamin Taş tarafından doktora tezi olarak hazırlanmış ve yayımlanmıştır. 7

\section{Dîvân-ı Mesâbîh}

Kuloğlu Şeyh Hacı İlyas'ın 1045/1635-36 yılında kaleme almış olduğu Divân-ı Mesâbih, ilk sekiz manzume dışında tamamıyla hadislerin açıklandığı, 4 mesnevi 401 kasideyle toplam 405 şiirden oluşan hacimli bir eserdir. Baştan sona hadislerin açıklandığı bu eseri Türk Edebiyatında öteden beri yazılmış olan Kırk Hadis geleneğiyle değerlendirmek mümkündür.

Bilindiği üzere Türk Edebiyatında manzum ve mensur birçok kırk hadis tercümesi yazılmıştır. Bunların ekserisi de 16. ve 17. Yüzyılda kaleme alınmıştır. Abdülkadir Karahan (1953); bu yüzyıllarda yazılan toplam sayının 81 olduğunu ve bunların 16.sının 16.yüzyılda ve 13.ünün de 17. Yüzyılda yazılmış olduğunu belirtmiştir. Kemal Ümmî (ölm. 880/1475?), Nevayî (1441-1501), Fuzulî (ölm. 963/1556), Nev'î (1533-1598), Âşılk Çelebî (trc. 979/1571), Lâtifî (ölm. 990/1582), Âlî (1541-1600), Hakanî (trc. 1011/1603), Okçu-zâde Mehmed (1039/1630), Kefeli Feyzi (ölm. 1025/1616), Nâbî (ölm. 1124/1712), Taib (trc. 1120/ 1708), Antakyalı Münif (trc. 1146/1733) kırk hadis tercümesi yazan şairler arasında zikredilebilir. Türk şâirlerinin kırk hadîs tercümeleri ile ilgilenmelerinde, XV. asrın ikinci yarısından itibaren, Abdurrahman Câmî’nin (1414-1492) geniş ölçüde tesiri olmuştur. Nevayî, Fuzulî, Rihletî, Nabî, Münif'in risaleleri, Câmî'nin Erbaîn'inin tercümeleridir.

Ya değişik hadis kitaplarından alıntılar yaparak kırk hadis yazanlar olmuş, ya da kendilerinden önce âlimler ve edipler tarafından yazılmış olan kırk hadisleri tercüme ederek bu alana katkı sağlayan birçok münevver yetişmiştir. Türkçe kırk hadis mütercimleri arasında ön safta, kemiyet ve keyfiyet bakımlarından, şairler gelmektedir. Ulemâ ve ehl-i tarik de az değildir. (Karahan, 1953). Bunların

Şeyh Hacı İlyas (1045/1635), Dîvân-ı Hümâyûn, Beyazıt Devlet Kütüphanesi, No: 3596

Kuloğlu Şeyh Hacı İlyas Bâ̆̆ ı Behişt (2 Cilt Takım) (2015) Haz: Bünyamin Taş Serüven Yayınevi, 1. Baskı, $1082 \mathrm{~s}$.

Adres

Kırklareli Üniversitesi, Fen Edebiyat Fakültesi, Türk Dili ve Edebiyatı Bölümü, Kayalı Kampüsü-Kırklareli/TÜRKIYE e-posta: editor@rumelide.com 
manzum yazılanlarında, nazım şekli olarak, kıt'a ya da mesnevi şekilleri; vezin olarak da, çoğunlukla aruzun: "Feilâtün Mefâilün Feilün, Fâilâtün Fâilâtün Fâ̂lât, Müfteilün Müfteilün Feilün" vezinleri kullanılmıştır.

Kırk hadis yazma geleneği çoğunlukla Hz. Muhammed (s.a.v)'in meşhur: "Kim ümmetim için kurk hadis ezberlerse, Allah Azze ve Celle onu knyamet gününde fakih bir âlim olarak diriltir." Hadisine dayanmaktadır. Bu hadis hemen hemen bütün kırk hadis tercüme ve şerhlerinin dibâcelerinde zikredilmiştir.

Değerlendirmesini yaptığımız Divan-ı Mesâbih; İslam âleminde büyük şöhret kazanarak kırktan fazla şerhi yapılan, Ferrâ el-Begavî [ölm. 516/1122] tarafından kaleme alınmış olan Mesâbîhü’s-Sünne adlı hadis kitabının Âlim Sinan Efendi tarafından Türkçeye tercüme edilen "Tercüme-i Mesâbihü’s-Sünne"9 adlı eserinin nazma çekilmiş halidir. Âlim Sinan Efendi Halvetiyye tarikatının Uşşâkiyye kolu şeyhlerindendir. Aynı zamanda Âlim Sinan Efendi’nin halifesi de olan Kuloğlu, bir nevi sebeb-i telif manzumesi olan ve Âlim Sinan Efendiye ithaf ettiği 7. şiirinin aşağıdaki beyitlerinde eserini şu şekilde tanitmaktadır:

İşit kim yine sultân-ı meşâyih

Sinân Efendi ol cân-ı meşâyih

İçürdi baňa bir câm-ı mürüvvet

'Iyân oldı hep 'irfân-ı meşâyih

Anuň bezminde bu cân oldı mahmûr

Yazıldı ḳalbe dîvân-ı meşâyih

Bu kez nefs atına oldum süvâre

Kanı dèyü o meydân-ı meşâyih

'Azîmet eyledüm sadr-1 visâle

Göründi çünkim eyvân-ı meşâyih

Mesâbîhun ol idi tercümânı

Sözidür cümle tibyân-ı meşâyih

Anuň dürrini çün dizmek murâdım

Ola ol la'l-i mercân-ı meşâyih

Ki nesrin nazm ile te'yîd èderem

Çü şöhret bula ‘unvân-ı meşâyih

8 Buhari, Tarih (3/141); Ebu Nuaym, Hilye (4/189).

9 Âlim Sinan Efendi, Tercüme-i Mesâbihü’s-Sünne, Manisa İl Halk Kütüphanesi, Arşiv No: 45 Ak Ze 216/1, v. 1b -265a 
Yazam bir bir ehâdîs-i resûlü
Biline nice erkân-ı meşâyih

Çü Haḳk tevfiḳ èdüben ben żaîfe

Ola yardımcı rûhân-ı meşâyih

Eserde toplam 405 şiir bulunmaktadır. Bu şiirlerin 4'ü hariç tamamı kaside formundadır. Divan-ı Mesâbih, kasidelerin revi harflerine göre alfabetik olarak tertip edilmiştir. İlk 8 kaside dışında tamamı hadislerin tercümesi bağlamında nazmedilen bir eser olmakla birlikte şiirlerin muhtevası belirlenirken klasik tertip usulü de göz önünde bulundurulmuştur. Buna göre ilk şiir münâcât; ikinci şiir naat; sırasıyla üçüncü, dördüncü, beşinci ve altıncı şïrler Hz. Ebubekir, Hz. Ömer, Hz. Osman ve Hz. Ali övgüsünde birer methiye; 7. şiir ise Âlim Sinan Efendi vasfında bir methiyedir. Bu methiyeden sonra ise Sultan IV. Murat övgüsünde bir kaside gelmektedir. Eser bütünüyle 1. şiirden itibaren kasidelerin revi harflerine göre alfabetik olarak sıralanmıştır. Eserde önce Arapça metniyle ilgili hadis verilmiş ve daha sonra o hadisin açıklaması yapılmıştır. Eser, bu yönüyle sayı olarak olmasa da bir bakıma oldukça hacimli bir kırk hadis (40o hadis) özelliği arz etmektedir.

Toplamda 401 kaside ve 4 mesnevi ihtiva eden eserde bu şirlerin 397 tanesi Peygamber Efendimiz'in (s.a.v) bir hadisiyle ilgilidir. Sadece ilk 8 kaside övgü mahiyetinde olup sonrakiler başlıkta verilen ilgili hadisin tercümesi şeklindedir. Eserin sonunda ise tekrar başa dönülmüş ve sirasılyla dört halifenin faziletlerinin anlatıldığı hadisler verilerek tercümeleri yapılmıştır. Daha sonra mesnevi nazım şekliyle Aşere-i mübeşşere, Ehl-i beyt, Şam ve Yemen'in fazileti hakkında birer hadis ve tercümesi, en sonunda da "Ümmetimin, evveli mi sonu mu daha hayırhdır kesin bilinmeyen yağmur gibidir." verilerek şu beyitlerle hâtime yapılmıştır.

\section{Bi-hamdi'llâh kitâb erdi tamâma}

Hezârân şükr ola ol lâ-yenâma

Selâm ısmarladım bâd-ı sabâya

İrüre gûş-1 zülf-i Mustafâya

li-muharririhi'l-hakîr ve ketebehü'l-fakîr eş-şeyh el-hâcc İlyâs emenehu'llahü min şerri'l-vesvâs eşşehîr bi-Kuloğlu rahimehü'-l üstâde sene 1045 /1635-3611

Dîvân-ı Mesâbih'de ilk önce ilgili hadis verilip daha sonra bu hadisin nazmen açılaması yapılmıştır. Her bir hadis için ayrı bir kaside yazılmıştır. Bazen verilen hadisle ilgili bir ayet-i kerime yazılıp onun da açıklaması yapılmaktadır. Eserde daha önce de belirttiğimiz gibi şiirlerin revi harflerine göre alfabetik olarak tertip edilmiş alfabe harfleri bitince tekrar baştan başlanmıştır. İlk 29 şiir 10'ar beyitten oluşmakta ve ilk olarak Cibril Hadisi12 ismi verilen iman, İslam, ihsan ve kıyamet alametleri gibi bazı soruları içeren hadisin tercümesi şeklindedir. Daha sonraki hadisler ise 20'şer beyitten oluşmaktadır. Bu hadisler namaz, oruç, sadaka, Allah için sevmek ve Allah için buğz etmek, müminin nasıl olması gerektiği, büyük günahlar nelerdir, cennet ve cehennem ehli olanlar kimlerdir, Âdem’in yaratışı,

İbni Mâce, II, 1319, no:3987.

Dîvân-1 Mesâbîh, Tavşanlı Zeytinoğlu İlçe Halk Kütüphanesi, No:43 Ze 362, v. 281ª.

Cebrail aleyhisselâm, Hz. Peygamber'in de aralarında bulunduğu bir sahabe' topluluğuna insan suretinde gelmiş, iman, İslâm, ihsan ve kıyamet alâmetleri gibi bazı soruları Allah Rasûlüne sorarak cevaplarını almıştır. İşte Cebrail (a.s.)'in bizzat soru sorarak ve cevaplarını tasdik ederek telkin ettiği bu hadise "Cibril hadîsi" adı verilmiştir. 
münafığın alameti nelerdir, ilmin ve âlimlerin üstünlüğü, abdest, gusül, mesh, temizlik, namaz vakitleri vb. bütün dinî konuları içermektedir. Bazen ilgili hadisin bir kısmı verilerek ilk 10 beyitte açıklanmış daha sonraki kısmı verilerek devamında açıklanmıştır. El-Begavînnin Mesâbihü's-Sünne'sinde toplamda 4931 adet hadis vardır. (Hatipoğlu, 2004: 258). Âlim Sinan Efendi’nin tercümesinin hacmi dikkate alındığında da bu rakama yakın bir mevcudun olduğu söylenebilir. Kuloğlu'nun eseri ise hacim bakımından Âlim Sinan Efendi’nin tercümesinden daha küçüktür. Söz konusu tercüme doğrultusunda düzenlenmiş manzum bir eser olduğu dikkate alındığında Kuloğlu'nun, Âlim Sinan Efendi'nin eserini özetleyerek tanzim etmiş olduğu ortaya çlkmaktadır. $\mathrm{Bu}$ hacmiyle eserde yaklaşık 7850 beyit bulunmaktadır. Dîvân-ı Mesâbîh’in bilinen iki nüshası vardır. Bu nüshalardan birisi Tavşanlı Zeytinoğlu İlçe Halk Kütüphanesi'nde (Arşiv no: 43 Ze 362), diğeri ise Beyazıt Devlet Kütüphanesi’nde (demirbaş no: B1222) yer almaktadır. Mesâbih'in Tavşanlı nüshası Divan-ı Hümayun'la aynı tarihte (hicri:1045/ 1635-36) yazılmış olup ikisi de müellif hattı olması bakımından değerlidir.

Türk Edebiyatında sayı olarak kırk hadis yerine bunun katları şeklinde eserler yazanlar da olmuştur. Bunlardan biri de Usûli'dir. Divanının baş tarafında "Manzûme-i Hadîs-i Erbaîn" adıyla yer alan manzum kitalarda seksen hadis tercüme edilmiştir. Türk ve İran edebiyatında 80 (2x40 veya 120 (3x40) hadisi nazma çekenler yahut 100 hadisi kırk hadis niyetine tercüme ve şerh edenler de görülmekte ve Usûlî bunlar arasında yer almaktadır. (Karahan, 2002: 471)

Bunun yanı sıra az sayıda 100 hadis tercümesi de vardır. Latifi Abdüllatif Çelebi'nin (ö. 990/1582) Subhatü'l-uşşâk'ı bu türden manzum bir tercümedir. Aruzun "Feilatün Mefailün Feilün" kalıbıyla yazılan eserin bir nüshası Nuruosmaniye Kütüphanesi'nde kayıtlıdır (nr. 4897). Türk edebiyatında "güli sad-berk" olarak da adlandırılan 100 hadis tercüme ve şerhleri mevcut olduğu halde 1000 hadis türünün örneklerine rastlanmamıştır. Necip Fazıl Kısakürek'in de çeşitli konular altında toplayarak ikişer mısra ile tercüme ettiği 101 Hadis adlı bir eseri vardır. (Karahan, 2002: 473)

Dîvân-ı Mesâbîh’in orijinal niteliğini yansitan bir manzumeyi örnek olarak aşağıda veriyoruz. Örnekte Kuloğlu, vesvese başlığı altında Ebu Hureyre (r.a.) Hazretlerinin Peygamber Efendimizden (s.a.v.) rivayet ettiği ve "Allahü Teâlâ bu ümmetin (söylemedikleri ve yapmadıkları müddetçe) kalplerinden geçen vesveseleri bağışlamıştı" "13 hadisini nazmen tercüme etmiştir.

\section{Örnek:}

faslün fi'l-vesveseti revâhu Ebû Hureyretü kâl enne'llâhe tecâveze 'an ümmetî mâ vesvesetü sudûrihâ

Vezin: fâilâtün / fâilâtün / fâilâtün / fâilün

1 Gelberu tut âşı is iseň sen de bu râza ḳulak

Bu şerî‘at bezmi içre çalınan sâza ḳulak

2

Râvisidür Bû Hureyre hażreti ol serverün̆

‘Âkil iseň tutagör güftâr-ı mümtâza ḳulak 
Vesvese-i hâtırasından tut o nâza ḳulak

4

Kim sudûr-ı ümmete ḳllsa tasaddur sû-i hâl

Gelmese fi'le dèdi tut sen o şehbâza ḳulak

$5 \quad$ Haḳk te âlâ dèr tecâvüz ède andan serteser

'Afv ėde cürmin o ḳuluň tut buňa tâze ḳulak

6 Şol ki izhâr olmadı Haḳk anı izhâr ètmeye

Setr ėde settâr-ı 'âlem kim anı yaḳın ırak

\section{İn tübtû mâfî enfüisiküm ev tuhfûhu yuhâsibküm bihi'llah.. ${ }^{14}$}

$7 \quad$ Kầzî̀ Beyżâvî çü tefsîrinde buyurmışdurur

Sû-i hâtır yerleşüp göňülde ḳalsa baş ayak

8 'Âkılbet ol 'afv olunmayup muhâseb oluna

Dėyü buyurmışdurur ol ḳalbüň eyle iki şâk

9 Sordılar ba‘żı sahâbe fahr-i 'âlemden yine

Dėdiler kim yâ Resûla'llâh bize olg̀ıl anak

10 Şöyle kim sû-i havâtır ḳalbümüzde bulınur

Biz ta‘âzüm èderüz söylemege anı beyak

11 Ol tekellümden te‘âzüm ètdürür dâim bizi

Nefsümüzde buluruz biz dèdiler aňa surâk

12 Anlara sordı yine dönüb resûl-i Kirdgâr

Siz anı vicdânıňuzda bulduňuz mı berr ü bâk

13 Dėdiler ḳâlû ne‘am vicdânımuzda yâ resûl

Buluruz dâim anı ne ḳılalum bârî berâk

14 İşbu vesvâs-1 şeyâtîn sû-i hâtırdur bize

Bu èyü ‘amellerümüz ile yemm-i infisâk

15 Nitekim zinâ livâta hâtırı şehvâniye

İçümüzde kim tulû‘ èder gamı og̉lân uşâk

$14 \quad$ Bakara / 284 
16

Ahmed-i muhtâr işidüb dèdi anlara kelâm

Fikriňüz a'mâle gelmedükçe bulmazsız dûzâh

17

Hem dėmişdür anlara budur çün îmân-ı sarîh

İctinâb ėdersiz anı söylemege intifâh

18

Vesveseyi dèmeyüb gördükçe siz cürm-i ‘aẓ̂m

Ola cennetde firâşıňuz maḳ̂am-ı müşg-i nah

19

Pes buyurdı dahi şeytân èder insâna hulûl

Kan ile bile tamarlarda ḳılur tâ insilâh

20

Ėy Kuloġlı Haḳ te‘âlâya tazarru‘ ḳıl müdâm

Ḳılmaya sû-i havâtır beyt-i ḳalbüň infisâh ${ }^{15}$

\section{Sonuç}

Türk Edebiyatında çok sayıda kırk hadis tercüme ve şerhleri yapılmıştır. Sayı olarak kırk hadis yerine bunun katları şeklinde eserler yazanlar da olmuştur. 80 (2x40) ya da 120 (3x40) şeklinde veya 100 hadisi kırk hadis yerine tercüme edenlere rastlanmıştır. Örneğin Usûlî "Manzûme-i Hadîs-i Erba în" adıyla seksen hadis tercüme etmiştir. Ancak Kuloğlu gibi bütün bir divanını tamamen hadislerin tercümesiyle tertip etmiş olan başka bir şaire rastlanılmamıştır.

Kuloğlu, şiirlerinde tatbik ettiği form bakımından da bütün bir edebiyat tarihimiz içinde istisnadır. Çünkü onun şiirlerinin çoğunluğu kaside nazım şekliyle yazılmıştır. Kuloğlu, 1200'den fazla kaside yazmıştır ki, eldeki verilere göre klasik Türk edebiyatının en çok kaside yazan şairidir. Toplamda 25000 beyitlik bir yekûna ulaşan üç büyük divanının (Dîvân-ı Hümâyûn, Dîvân-ı Mesâbîh ve Bâğ-ı Behişt) tamamına yakını ve toplamda 2000 beyit civarındaki Etvâr-ı Seb'a'nınsa 60 kadar şiiri kaside nazım şekliyle yazılmıştır.

Etvâr-ı Seb’a ve Dîvân-ı Mesâbih’te müstezad ve mesnevi nazım şekliyle yazılmış birkaç şiir mevcutsa da Kuloğlu, mezkûr üç nazım şeklinin dışında başka bir nazım şekliyle şiir yazmamıştır. Bu durum Kuloğlu'nun, kendi orijinal formunu takip etme hassasiyetinde olduğunu göstermektedir. Bu form, ekseriyetle 20 beyitten oluşan kaside formudur. Mezkûr üç büyük eserinde kasidelerin tamamına yakını 20 beyitten oluşmaktadır. Elimizdeki bilgilere göre Klasik Türk edebiyatında tamamı yirmişer beyitlik kasidelerden oluşan eser yazma gibi bir gelenek yoktur. Dolayısıyla yirmişer beyitlik kasidelerden oluşan eser yazma Kuloğlu'na ait bir tarz olarak kabul edilebilir.

Bütün bunlar değerlendirildiğinde Kuloğlu'nun Dîvân-ı Mesâbih'i, hem sayı olarak hem de yöntem olarak diğer yazılan kırk hadis eserlerinden farklılık arz etmekte ve bizce orijinal bir eser olma niteliğini elde etmektedir. 


\section{Kaynakça}

Bursalı, M. T. (1333). Osmanl Müellifleri, C. I, İstanbul: Matbaa-i Amire.

Hatipoğlu, İ. (2004). Mesâbihu’s-Sünne Türkiye Diyanet Vakfi İslam Ansiklopedisi. C.29

Karahan, A. (1953). Kırk Hadis Tercümelerine Umûmî Bir Bakış ve Ankaralı İsmâil Rüsûhî’nin “Tercüme-i Hadîs-i Erbaîn”'i, Türkiyat Mecmuası, X. Cilt, İstanbul: Osman Yalçın Matbaası.

Karahan, A. (2002). Krrk Hadis Türkiye Diyanet Vakfi İslam Ansiklopedisi, Cilt:25.

Kocatürk, V. M. (1970). Türk Edebiyatı Tarihi, Ankara: Edebiyat Yayınevi.

Köksal, M.F. (2011). Mevlid-nâme, Ankara: TDV

Pekolcay, N. (2005). Süleyman Çelebi-Mevlid, İstanbul: Dergâh Yayınları.

Şengün, N. (2015). Kuloğlu Şeyh İlyâs, Etvâr-ı Seb’a, 2. Basım, Ankara: İlahiyat Yayınları

Taş, B. (2013). Kuloğlu Şeyh Hacı İlyas Külliyatı Akademik Bakış Uluslararası Hakemli Sosyal Bilimler E-Dergisi, sayı:35.

Taş, B. (2014). Kuloğlu Şeyh Hacı İlyas Bâ̆̆-ı Behişt, (inceleme-Tenkidli Metin) Trakya Üniversitesi Sosyal Bilimler Enstitüsü Doktora Tezi.

Vassaf, H. (t.siz). Sefine-i Evliyâ-yı Ebrâr (Cilt IV). İstanbul: Süleymaniye Kütüphanesi Yazma Bağışlar No: 2308 